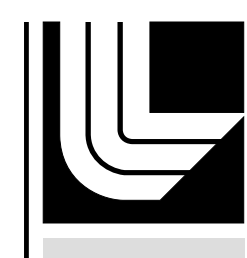

LAWRENCE LIVERMORE N A T IO N A L LABORATORY

\title{
Characterization of Recompressed Spall in Copper Gas Gun Targets
}

\section{UCRL-JRNL-224017}

R. Becker, J.U. Cazamias, M.M. LeBlanc

August 28, 2006

Journal of Applied Physics 
This document was prepared as an account of work sponsored by an agency of the United States government. Neither the United States government nor Lawrence Livermore National Security, LLC, nor any of their employees makes any warranty, expressed or implied, or assumes any legal liability or responsibility for the accuracy, completeness, or usefulness of any information, apparatus, product, or process disclosed, or represents that its use would not infringe privately owned rights. Reference herein to any specific commercial product, process, or service by trade name, trademark, manufacturer, or otherwise does not necessarily constitute or imply its endorsement, recommendation, or favoring by the United States government or Lawrence Livermore National Security, LLC. The views and opinions of authors expressed herein do not necessarily state or reflect those of the United States government or Lawrence Livermore National Security, LLC, and shall not be used for advertising or product endorsement purposes. 
UCRL-JRNL-224017

\title{
Characterization of Recompressed Spall in Copper Gas
}

\section{Gun Targets}

\author{
R. Becker and M.M. LeBlanc \\ Lawrence Livermore National Laboratory, Livermore, CA 94550 \\ J.U. Cazamias \\ University of Alabama, Birmingham, AL 35294
}

Complementary experiments and simulations are conducted to characterize the microstructure and mechanisms involved in recompression of spalled ductile metals. Soft capture experiments performed on copper targets in a gas gun include a dense secondary plate spaced behind the customary flyer to recompress the voids in the wake of the spall induced by the flyer. Control experiments are run without the secondary plate to obtain spall damage without recompression. The simulations feature explicit representation of void nucleating particles in a narrow strip of material spanning the flyer package and target. Analysis of the spall closure in the simulations reveals the void collapse mechanisms and the origin of features observed experimentally. The experiments and simulations show little trace of the prior voids, and a thin ribbon of highly strained material is the only readily observable remnant of the spall surface. 


\section{INTRODUCTION}

Materials subjected to dynamic loading from high velocity impacts, explosive drives or laser ablation frequently incur internal damage in the form of spall. Spall in ductile metals is caused by nucleation and growth of voids under tensile loading conditions created by the interaction of stress waves with surfaces and interfaces. When compressive shock waves reflect off of low-impedance surfaces and interact, a tensile stress state can be created. If the tensile stress is sufficiently high, voids can nucleate around particles or defects in the material and grow. Spall and the resulting damage have been studied extensively for shock loading created by gas guns ${ }^{1-4}$, explosives ${ }^{5-8}$ and laser ablation ${ }^{9-11}$.

In many dynamic loading applications the material continues to deform after spall occurs. Simulations of such dynamic events must be able to track the post-spall deformation reliably, so it is important to understand the mechanisms involved. The particular post-spall deformation of interest here is closure of the spall by continued loading. This situation arises for explosive drives when the material pushed directly by the explosive catches up to and impacts a previously spalled layer. Recompression of spall can also occur when spalled materials impact other structures, such as in debris shields or layered armor. The behavior of a closing spall surface under dynamic loading is anticipated to resemble explosively welded interfaces ${ }^{12}$ and shock compacted materials ${ }^{13,14}$. Some research has been done to examine the bonding mechanisms for these processes $^{15}$.

Since little is known about recompressed spall, a vital step is to characterize the salient microstructure features in metallographic sections of recovered samples and to identify the processes creating the features. The goal of this work is to describe the appearance of recompressed spall and to provide insight into the mechanisms. The observations and conclusions 
are based on complementary experiments and simulations of spall and recompression in copper gas gun targets.

\section{EXPERIMENTS}

\section{A. Experimental configuration}

Experiments were performed on high purity copper using a $35 \mathrm{~mm}$ light gas gun at Lawrence Livermore National Laboratory. The design of the target and flyer package for the combined spall and recompression tests is shown in Figure 1. The flyer package contains a $2.7 \mathrm{~mm}$ thick aluminum flyer plate backed by a $1.3 \mathrm{~mm}$ thick polycarbonate disk followed by a $3.0 \mathrm{~mm}$ thick tantalum slug. This is all encased in a polyethylene sabot. The $4.0 \mathrm{~mm}$ thick target includes additional momentum trap rings to mitigate release effects during the initial spall.

Laser interferometry is used to provide a velocity time history of the free surface at a temporal resolution of $0.02 \mu$ s (microsecond). The technique employs a thin mirror that is shattered as the specimen proceeds down the target chamber. The target then passes through a 20 mm diameter steel stripper tube to remove the momentum trap rings. The center portion of the target is then soft-captured in a cylinder filled with layers of expanded polystyrene.

The aluminum flyer impacting the copper target launches compressive waves in both. The waves reflect from the free surface of the target and from the aluminum-polycarbonate interface in the flyer. The reflected waves meet at roughly the mid-plane of the target to create a tensile stress that spalls the copper target. The compression wave in the aluminum flyer also compresses the polycarbonate disk against the tantalum slug in the flyer package. The stress in the polycarbonate disk rings up and creates a recompression wave that follows the release wave through the aluminum flyer and into the copper target. This second compression pulse closes the spall. Since 
the recompression pulse is generated by compressing the polycarbonate disk, the pulse has a significantly longer rise time than the wave from the initial impact. Results from a simulation showing the stress fields predicted in the spall and recompression phases are given in Figure 2.

The loading in these experiments is not purely longitudinal. Radial release waves from the initial impact will reach the center of the target before the recompression is complete. These 3D effects are tolerated since the goal of the experiments is simply to recompress spall and examine the recovered specimen. A quantitative wave profile analysis is not attempted. Non-ideal loading is also acceptable because components spalled and recompressed in actual applications will not undergo ideal loading. Hence, achieving 1D conditions is not necessary to create a relevant microstructure.

Control experiments were run using a similar design but without the tantalum slug. Polycarbonate occupied the entire space behind the aluminum flyer. This induces the same spall stress without the subsequent recompression pulse. The spall in these recovered samples will be comparable to the initial spall induced in the experiments described above.

\section{B. Characterization of void nucleation sites}

Incipiently spalled (the spall plane is not completely separated) control specimens created without the tantalum slug in the flyer package were used to characterize the extent of spall and the void nucleation sites. Cross sections of the disk were first examined optically to verify the presence of pervasive void damage associated with spall, Figure 3. Small tensile specimens were then machined from the targets with the tensile axis being the $4.0 \mathrm{~mm}$ thickness of the disk. These were pulled to fracture, and the fracture surfaces were examined in a scanning electron microscope. Dimples, characteristic of ductile fracture, are evident in Figure 4a. The sub-micron sized particles revealed in Figure 4b are assumed to be the void nucleation sites. 
Compression tests were also run on cylindrical specimens cut from the incipiently spalled targets. Quasi-static and Hopkinson bar compression tests did not close the porosity even though

the specimens were deformed $15 \%$. As in the work of Gray and Bourne ${ }^{16}$, these specimens exhibited considerable strain hardening in the vicinity of the voids which prevented closure. Higher pressures, such as those achievable in a gas gun, are required to close the voids. The simulations in Figure 2 show a compressive stress of 2.5 GPa from gas gun experiments. This is an order of magnitude higher than the stress achieved in the Hopkinson bar tests.

\section{Experimental results}

Optical micrographs of the incipiently spalled control samples (without the tantalum slug) run at 165 and $220 \mathrm{~m} / \mathrm{s}$ flyer velocities are shown in Figure 5. A pattern of isolated voids is seen for the lower velocity, while the porosity is nearly fully connected for the higher impact velocity.

Micrographs at the same through-thickness location and at the same magnification are shown in Figures 6 and 7 for experiments at 165 and $220 \mathrm{~m} / \mathrm{s}$, respectively, using flyers containing the tantalum slugs. Both sets of micrographs exhibit a feature running horizontally across the image that is inferred to be the remnant of the spall damage. The samples were heavily etched to ensure that voids were not smeared over during polishing. In support of this assertion, the ribbon feature in the $165 \mathrm{~m} / \mathrm{s}$ micrographs shows residual porosity. The images in Figure 6 also show isolated voids above and below the ribbon. These are consistent with the off-plane voids evident in Figure 5a. The micrographs suggest that $165 \mathrm{~m} / \mathrm{s}$ is near the threshold velocity for both spall and recompression. Near the threshold the results may not be consistent from shot to shot. Thus, further analysis will be focused on the $220 \mathrm{~m} / \mathrm{s}$ experiments.

The transverse feature from the $220 \mathrm{~m} / \mathrm{s}$ shot, Figure 7, shows no obvious residual porosity at this magnification. The feature appears in the same location on the sample thickness as does the 
spall on the control sample, Figure 5b, and there is no evidence of the spall plane having existed elsewhere in the specimen. Image quality and grain orientation maps using electron back scatter diffraction (EBSD) are given in Figure 8. The dark-shaded image quality index in Figure 8a indicates a poorly resolved diffraction pattern. This is typically associated with a highly dislocated microstructure or a fine grain size. The false-color image in Figure 8b shows grain orientations that the EBSD system was able to resolve. The orientations assigned in the ribbon suggest a small grain size, but those results are uncertain due to the poor image quality.

Higher resolution EBSD images in Figure 9 expose the remnants of the voids and the highly localized nature of the deformation. There appear to be discrete bands emanating from the collapsed voids. The orientation map, Figure 9b, shows that the bands may be rotated significantly from the parent grain orientation. The grain structure also reveals segments of grains that are nearly aligned on either side of the highly strained ribbon. This suggests that there was little overall transverse displacement associated with the deformation process.

Free surface velocity histories from the $220 \mathrm{~m} / \mathrm{s}$ experiments are shown in Figure 10. Results from the control and the recompressions test are plotted together to highlight the similarities and differences. The control test is indicated by the gray curve, and the black curve is the result with the tantalum slug inserted in the flyer. Both curves show approximately the same minimum velocity on the first pullback, and the subsequent rise and recoil are indicative of the stress pulse traversing the spalled layer. The recompression pulse is evident shortly after $3 \mu \mathrm{s}$, in agreement with the simulations. The rise is not nearly as steep as the initial loading pulse because the pressure driving the recompression builds up gradually in the polycarbonate layer between the aluminum flyer and the tantalum disk. At approximately $3.7 \mu$ s the black curve deflects and then continues to rise at the previous rate. It is inferred that this inflection is associated with recompression of the spall voids. 


\section{SIMULATIONS}

\section{A. Model description}

Modeling is used to investigate void interaction and interface mechanisms during spall recompression. A 3D model using the actual size of the particles shown in Figure 4b would be impractical, so a simplified configuration is employed. The plane strain model will exhibit many of the mechanisms of void opening and closing even if 3D features are not captured directly. Also, while the spall stress will depend on the size of the void nucleating particles, recompression of the spall voids is expected to depend primarily on the open void configuration and the compressive loading pulse. Thus, a larger initial particle size should not adversely affect closure predictions. The purpose of the simulations is to elucidate mechanisms, not to validate the model.

The gas gun experiments are modeled as a $200 \mu \mathrm{m}$ wide region along the centerline of the flyer and target using a plane-strain finite element model, Figure 11a. The width of the section was chosen to accommodate several $\sim 50 \mu \mathrm{m}$ diameter voids as seen in Figure 5. The copper target and the aluminum, polycarbonate and tantalum in the flyer package are all represented explicitly. The flyer region was discretized with 150 elements across the $200 \mu \mathrm{m}$ section. There are 2000, 1000 and 3000 elements, respectively, through the thickness of the aluminum flyer, polycarbonate and tantalum. The first $1.0 \mathrm{~mm}$ of the copper target is discretized with 300 elements across the $200 \mu \mathrm{m}$ section and 1500 elements in the $1.0 \mathrm{~mm}$ segment. The remaining $3.0 \mathrm{~mm}$ of the target was meshed with 600 elements across the $200 \mu \mathrm{m}$ section and 9000 elements for the $3.0 \mathrm{~mm}$ thickness. The transition in discretization was constrained as a tied slide surface. The use of only a few mesh transition regions and a regular rectangular grid is intended to minimize spurious wave reflections from mesh discontinuities. 
The flow strength for all materials is assumed to follow a simple power law and the equation of state is specified as the Grüneisen relation. The material parameters are taken from Steinberg ${ }^{17}$ and are given in Appendix A. The copper used in the experiments was in a half-hard state, and the constitutive model was fit for a nominally half-hard condition.

The copper target region was seeded using a constrained-random algorithm to achieve a $0.125 \%$ area fraction of $2.0 \mu \mathrm{m}$ diameter particles, Figure $11 \mathrm{~b}$. The particle size was based on mesh resolution considerations, and the area fraction was adjusted to produce a $50 \mu \mathrm{m}$ average spacing. This is roughly the void spacing in the spalled specimens. A constraint prevented particles from being closer than $40 \mu \mathrm{m}$. The particles are significantly larger than the particles shown in Figure 4, but the chosen mesh size and the accuracy of the mixed-material element treatment would not permit smaller particles, Figure 11c. The inclusions have the same properties as the surrounding copper when in compression, but they have no strength in tension. Hence, these regions will not perturb the transmitted shock but will expand freely in tension.

Simulations were run with the ALE3D ${ }^{18}$ finite element code developed at Lawrence Livermore National Laboratory using either 128 or 256 processors on a Linux cluster. The calculations were run in Arbitrary Lagrange-Eulerian mode where the mesh motion may be independent of the material motion. An equipotential algorithm was used for mesh relaxation in the most finely resolved region, and the remainder of the model was treated as Lagrangian. Since the mesh was initially rectangular, it remained nearly rectangular throughout the simulation.

Elements contain either a single material or two materials. Advection across boundaries of elements containing a single material is second order accurate ${ }^{19}$, and advection involving elements with two materials is first order accurate. In elements with multiple materials, the volume strain is apportioned to retain a common pressure for the two materials. The treatment of the interface is approximate, but it is sufficient for capturing the gross effects of opening and closing voids. 
Perturbations caused by the interface treatment diminish as volume to surface area of the voids increases.

Boundaries with normals orthogonal to the loading direction have zero normal velocity and zero shear traction. A uniform initial velocity is applied to all materials in the flyer package, and the target is initially at rest. Since the particles are considerably larger than those found experimentally and since the model is plane strain, the velocity required to initiate spall is considerably lower. Initial velocities of $165 \mathrm{~m} / \mathrm{s}$ and $220 \mathrm{~m} / \mathrm{s}$ were used.

\section{B. Simulation results}

Contours of plastic strain are shown in Figure 12 at several times for the $165 \mathrm{~m} / \mathrm{s}$ simulation. At $1.5 \mu$ s there is strong plastic interaction among the voids in the region that will later spall. By $2.0 \mu$ s the void growth is nearly at its full extent. The configuration is nearly the same at $2.5 \mu \mathrm{s}$. An important distinction, however, is the appearance of well developed localized plastic deformation bands connecting the voids at $2.5 \mu$ s. The beginning of the localization can be seen at the earlier time. A similar shear feature is seen in the experimental results of Gray and Bourne ${ }^{16}$. As the voids collapse, these highly sheared regions rotate, deform and become a more or less contiguous feature decorated with the remnants of the nearly closed voids.

With the $220 \mathrm{~m} / \mathrm{s}$ flyer velocity, the voids coalesce, and the target separates into two parts, Figure 13. Closure has begun by $2.6 \mu$ s, and the simulation shows sliding where the necked regions first contact in the lower portion of the figure. At $2.7 \mu$ s this sliding feature continues to grow. The necked regions in the upper portion of the plot begin sliding into each other, more or less like a plug in a hole. This continues through $2.8 \mu$ s where it is evident that the voids are not being squeezed shut; they are closed through this plugging mechanism with intense shear on the 
void walls. By $3.0 \mu$ s the voids appear fully closed and the ribbon of highly strained material delineates the prior spall surface. Plots of the configuration alone (without the strain contours) are very similar in appearance to the initial model.

Interfaces are not explicitly captured in this ALE formulation; the responses of the materials are simply averaged in the element. Thus, when the two interfaces come together, they are stuck. The interface sliding evident in Figure 13 and the strain localization in Figure 12 are highly localized shear strains facilitated by adiabatic heating rather than true sliding interfaces.

\section{CONCLUSIONS}

Both experiments and simulations of recompressed spall in a gas gun show localized, highly strained features running across the prior spall plane with little evidence of the prior voids. Based on these results, thin ribbons of highly strained material in components that experience spall-type loading and subsequent compression may be remnants of spall, even though voids cannot be readily observed.

The experimental and numerical approaches presented are complementary. Incomplete understanding of the torturous path of the highly strained ribbon in the micrographs motivated the simulations, and simulations provided insight into the mechanisms. It is concluded that the origin of the high strains is a combination of discrete bands between individual voids and void surfaces sliding over one another. Significant strain is induced as the voids close. The highly torturous path of the ribbon features is a result of the deformation and rotation of these shear bands and interfaces as spall collapse proceeds.

The energy required to distort the necked ligaments to accommodate the sliding is less than would be required to smash the ligaments or collapse the voids in a spherical deformation field. 
Although the 2-D nature of the model and the small model region constrain the deformation, the processes observed are expected to reflect the experimental void collapse mechanisms.

\section{ACKNOWLEDGEMENTS}

The contributions to this effort by Rich Couch, Neal Hinsey, Mukul Kumar and Adam Schwartz are greatly appreciated. Experimental funding was provided through LDRD 01-ERD032 and support for the modeling was through the ACS Dynamics of Metals program. This work was performed under the auspices of the U.S. Department of Energy by University of California, Lawrence Livermore National Laboratory under Contract W-7405-Eng-48. UCRL-JRNL-224017. 


\section{REFERENCES}

1 J.N. Johnson, G.T. Gray and N.K. Bourne: "Effect of pulse duration and strain rate on incipient spall fracture in copper," J. Appl. Phys, 1999, vol. 86, pp. 4892-4901.

2 J.M. Rivas, A.K. Zurek, W.R. Thissell, D.L. Tonks and R.S. Hixson: "Quantitative description of damage evolution in ductile fracture of tantalum," Metall. Mater. Trans. A, 2000, vol. 31A, pp. 845-851.

3 R.W. Minich, J. U. Cazamias, M. Kumar and A.J. Schwartz: "Effect of microstructural length scales on spall behavior of copper," Metall. Mater. Trans. A, 2004, vol. 35A, pp. 2663-2673.

4 X. Chen, J.R. Asay, S.K. Dwivedi and D.P. Field: "Spall behavior of aluminum with varying microstructures," J. Appl. Phys, 2006, vol. 99, Art. No. 23528.

5 S.A. Novikov, A.P. Pogorelov and L.M. Sinitsyna: "The formation of smooth spalls in steel during the interaction of glancing detonation-waves," Combustion Explosion and Shock Waves, 1994, vol. 30, pp. 537-539.

6 A.P. Rybakov: "Spall in non-one-dimensional shock waves," Int. J. Impact Engr., 2000, vol. 10, pp. 1041-1082. 
7 G.T. Gray, N.K. Bourne, B.L. Henrie and J.C.F Millett: "Influence of shock-wave profile shape (triangular -'Taylor-wave' versus square-topped) on the spallation response of 316L stainless steel,” J. de Phys. IV, 2003, vol. 10, pp. 773-778.

8 J. Buchar, J. Voldrich and S. Rolc: "Shock induced damage in austenitic stainless steel," Mater. Sci. Forum, 2004, vol. 465-456, pp. 67-72.

9 T. de Resse'guier, S. Couturier, J. David and G. Nie'rat: "Spallation of metal targets subjected to intense laser shocks," J. Appl. Phys, 1997, vol. 82, pp. 2617-2623.

10 K.S. Budil, E.R. Ault, T.A. Shepp, J.D. Colvin, W.E. King, H. Zimmermann, L. Hackel, M. Kumar, T. Clauson and R. Thoe: "Laser shock experiments investigating spall in metals," Abstracts the Amer. Chem. Soc., 2001, vol. 222, p. 36-NUCL.

11 M.S. Schneider, B. Kad, D.H. Kalantar, B.A. Remington, E. Kenik, H. Jarmakani and M.A. Myers: "Laser shock compression of copper and copper-aluminum alloys," Int. J. Impact Engr., 2005, vol. 32, pp. 473-507.

12 D.G. Brasher and D.J. Butler: "Explosive welding- principles and potentials," Adv. Mater. Proc., 1995, vol. 147, pp. 37-38.

13 M.A. Meyers, D.J. Benson and E.A. Olevsky: "Shock consolidation: Microstructurally-based analysis and computation modeling," Acta Mater., 1999, vol. 47, pp. 2089-2108. 
14 R.A. Austin, D.L. McDowell and D.J. Benson: "Numerical simulation of shock wave propagation in spatially-resolved particle systems," Modelling Simul. Mater. Sci. Eng., 2006, vol. 14, pp. 537-561.

15 I. Plaksin, J. Campos, J. Ribeiro, R. Mendes, J. Direito, D. Braga and R. Pruemmer: "Novelties in physics of explosive welding and powder compaction," J. de Phys. VI, 2003, vol. 110, pp. 797-802.

16 G.T. Gray III and N.K. Bourne: "Mechanical and substructural response of incipiently spalled 316L stainless steel," Dislocations, Plasticity, Damage and Metal Forming: Material Response and Multiscale Modeling, A.S. Khan and A.R. Khoei, eds., Neat Press, Maryland, USA, 2005, pp. 328-330.

17 D.J. Steinberg: "Equation of state and strength properties of selected materials," Lawrence Livermore National Laboratories report, 1996, UCRL-MA-106439.

18 "Users manual for ALE3D: an arbitrary Lagrange/Eulerian 3D code system," Lawrence Livermore National Laboratories, 2006, UCRL-MA-152204.

19 B. van Leer: "Towards the ultimate conservative difference scheme IV. A new approach to numerical convection," J. Comp. Phys., 1977, vol. 23, pp. 276-299. 


\section{APPENDIX A}

The form of the power law hardening relation used by Steinberg ${ }^{17}$ is

$$
\bar{\sigma}=\sigma_{0}\left[1+\beta\left(\varepsilon_{p}+\varepsilon_{0}\right)\right]^{n},
$$

where $\bar{\sigma}$ is the flow strength and $\varepsilon_{p}$ is the effective plastic strain. Although there are four constants in the relation, there only three independent parameters for this power law model.

The Grüneisen equation of state (EOS) is used to define the relationship among pressure, $p$, density, $\rho$, and specific energy, $e$. For material in compression the form is

$$
p=\frac{K_{0} \mu\left[1+\left(1-\frac{\gamma_{0}}{2}\right) \mu-\frac{b}{2} \mu^{2}\right]}{\left[1-\left(S_{1}-1\right) \mu\right]^{2}}+\rho_{0}\left(\gamma_{0}+b \mu\right) e \quad \mu \equiv \frac{\rho}{\rho_{0}}-1
$$

and for tensile states the form is

$$
p=K_{0} \mu+\rho_{0} \gamma_{0} e .
$$

The strain hardening and EOS parameters from Steinberg ${ }^{17}$ are given in Table I. 


\section{TABLE}

TABLE I. Material parameters used in the simulations

\begin{tabular}{|l|c|c|c|c|c|c|c|c|}
\hline & $\sigma_{0}(\mathrm{MPa})$ & $\beta$ & $\varepsilon_{0}$ & $n$ & $K_{0}(\mathrm{GPa})$ & $\gamma_{0}$ & $b$ & $S_{1}$ \\
\hline Copper & 120 & 36 & 0 & 0.45 & 138.6 & 2.20 & 0.47 & 1.49 \\
\hline Aluminum & 290 & 125 & 0 & 0.1 & 74.2 & 1.97 & 0.48 & 1.40 \\
\hline Polycarbonate & 2 & 5 & 0 & 0.1 & 4.4 & 0.61 & 0 & 3.49 \\
\hline Tantalum & 770 & 10 & 0 & 0.1 & 194.1 & 1.67 & 0.42 & 1.20 \\
\hline
\end{tabular}




\section{FIGURE CAPTIONS}

Figure 1. Material layout for gas gun flyer and target with momentum trap rings.

Figure 2. Simulations showing longitudinal stress during a) spall (1.7 GPa peak stress) and subsequent b) recompression (-2.5 GPa peak stress).

Figure 3. Incipiently spalled copper target from which tensile specimens were excised.

Figure 4. SEM micrographs of fracture surface showing a) void related dimples and b) sub-micron particles responsible for void nucleation.

Figure 5. Optical micrographs of control specimens for velocities of a) $165 \mathrm{~m} / \mathrm{s}$ and b) $220 \mathrm{~m} / \mathrm{s}$.

Figure 6. Optical micrographs of the recompressed target for the $165 \mathrm{~m} / \mathrm{s}$ flyer velocity.

Figure 7. Optical micrographs of the recompressed target for the $220 \mathrm{~m} / \mathrm{s}$ flyer velocity.

Figure 8. Electron backscatter diffraction images of recompressed $220 \mathrm{~m} / \mathrm{s}$ target: a) image quality and b) grain orientation.

Figure 9. Higher resolution electron backscatter diffraction images of recompressed $220 \mathrm{~m} / \mathrm{s}$ target revealing voids and larger grains cut by the prior spall surface: a) image quality and b) grain orientation.

Figure 10. Free surface velocity for b) $220 \mathrm{~m} / \mathrm{s}$ experiments.

Figure 11. Model description: a) overall geometry, b) particles in the cross section and c) uniform finite element discretization showing resolution of particles. 
Figure 12. Plastic strain contours at the spall region of the $165 \mathrm{~m} / \mathrm{s}$ simulation. For plots at $2.5 \mu \mathrm{s}$ and beyond the maximum contour level is set at 2.5 to highlight the highly localized nature of the deformation.

Figure 13. Plastic strain contours at the spall region of the $220 \mathrm{~m} / \mathrm{s}$ simulation. The maximum contour level is set at 4.0 to highlight the highly localized nature of the deformation. 


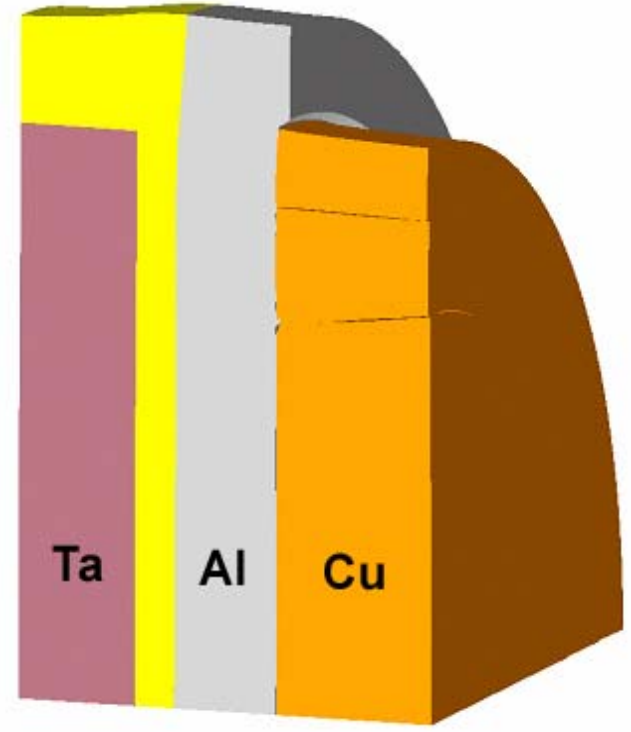

Figure 1. Material layout for gas gun flyer and target with momentum trap rings.
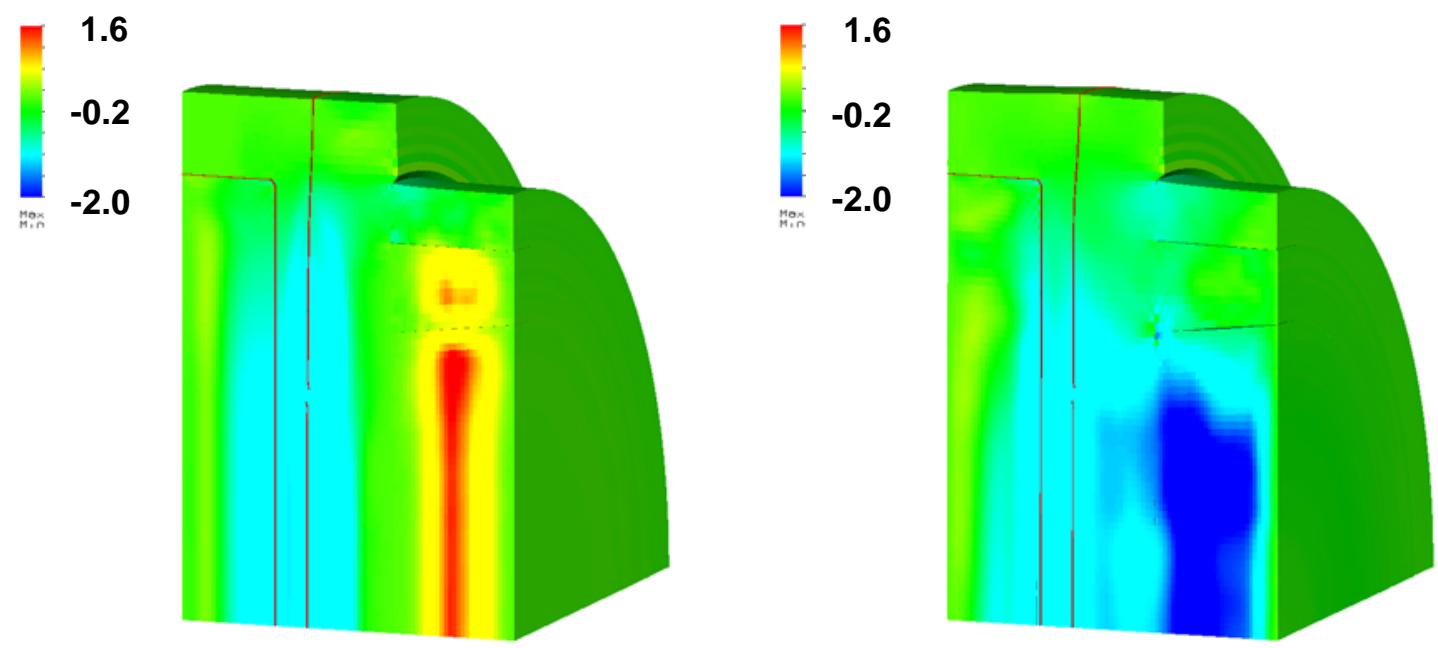

Figure 2. Simulations showing longitudinal stress during a) spall (1.7 GPa peak stress) and subsequent b) recompression (-2.5 GPa peak stress). 


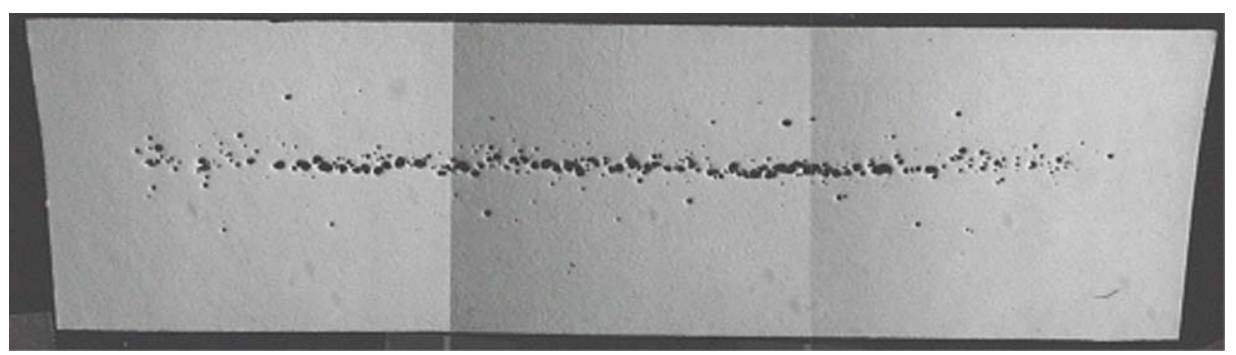

Figure 3. Incipiently spalled copper target from which tensile specimens were excised.
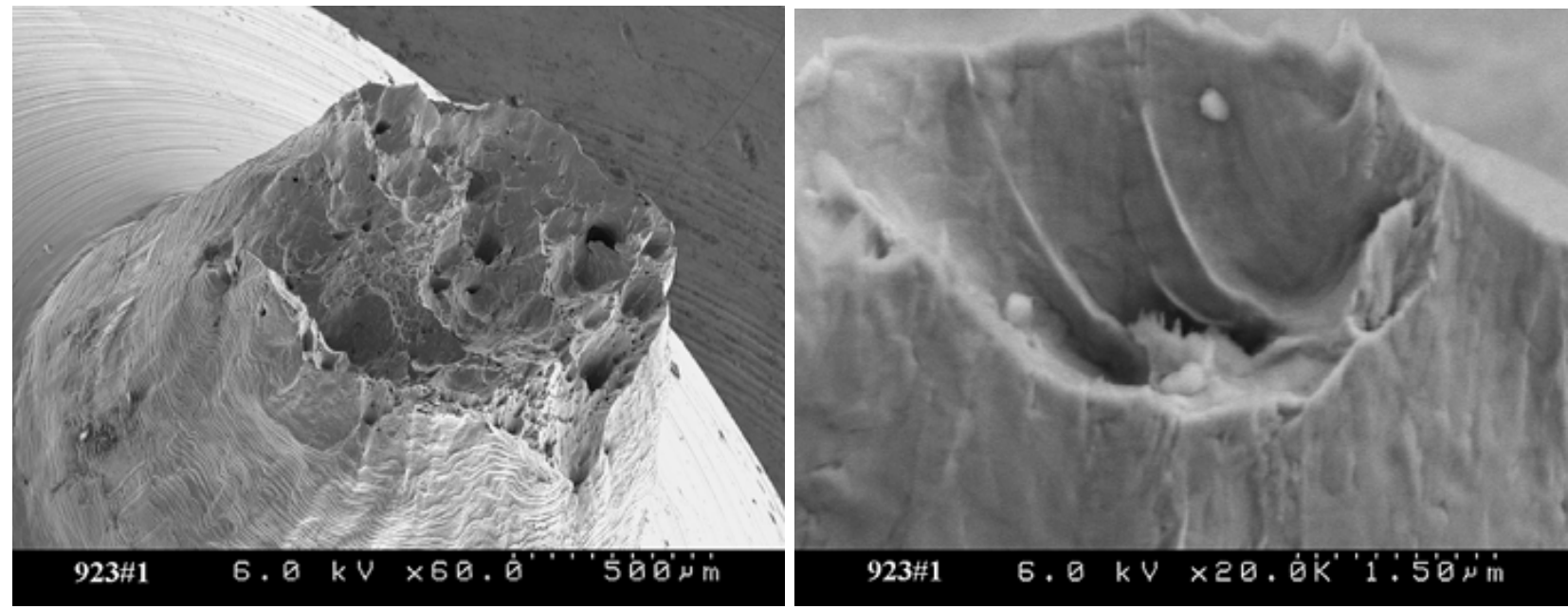

Figure 4. SEM micrographs of fracture surface showing a) void related dimples and b) sub-micron particles responsible for void nucleation.
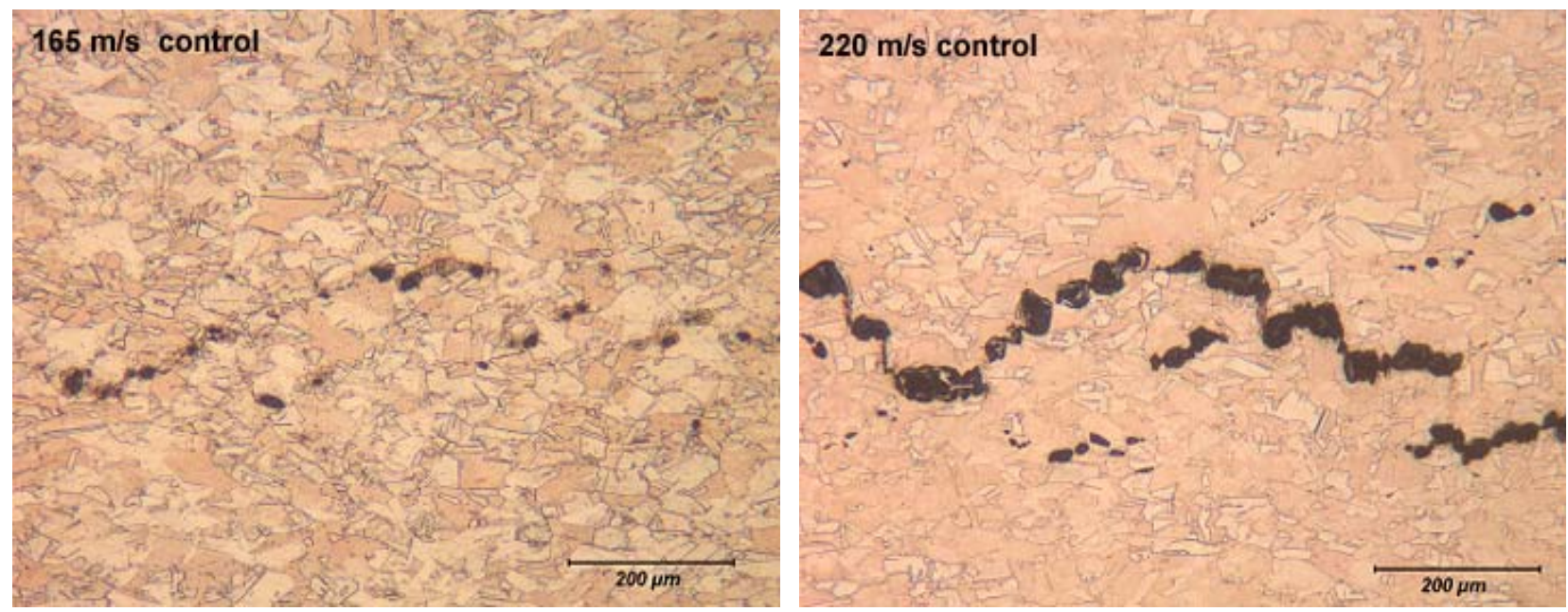

Figure 5. Optical micrographs of control specimens for velocities of a) $165 \mathrm{~m} / \mathrm{s}$ and b) $220 \mathrm{~m} / \mathrm{s}$. 

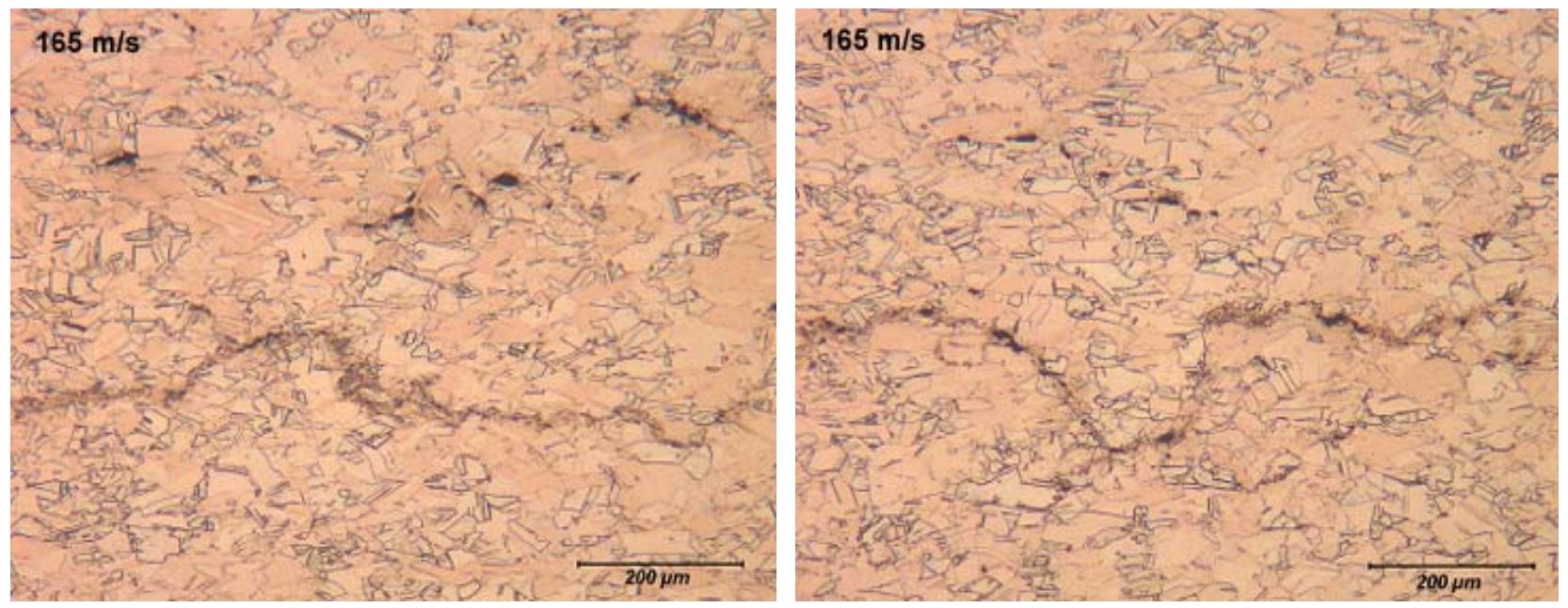

Figure 6. Optical micrographs of the recompressed target for the $165 \mathrm{~m} / \mathrm{s}$ flyer velocity.
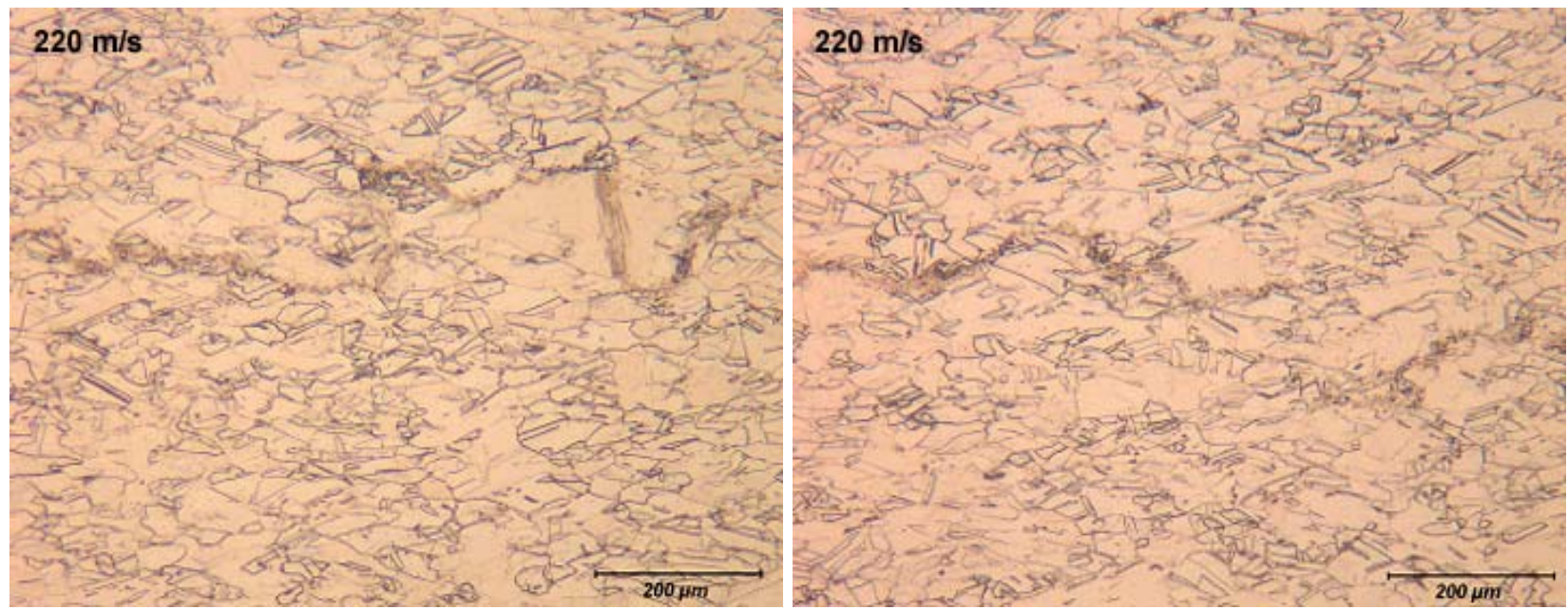

Figure 7. Optical micrographs of the recompressed target for the $220 \mathrm{~m} / \mathrm{s}$ flyer velocity. 

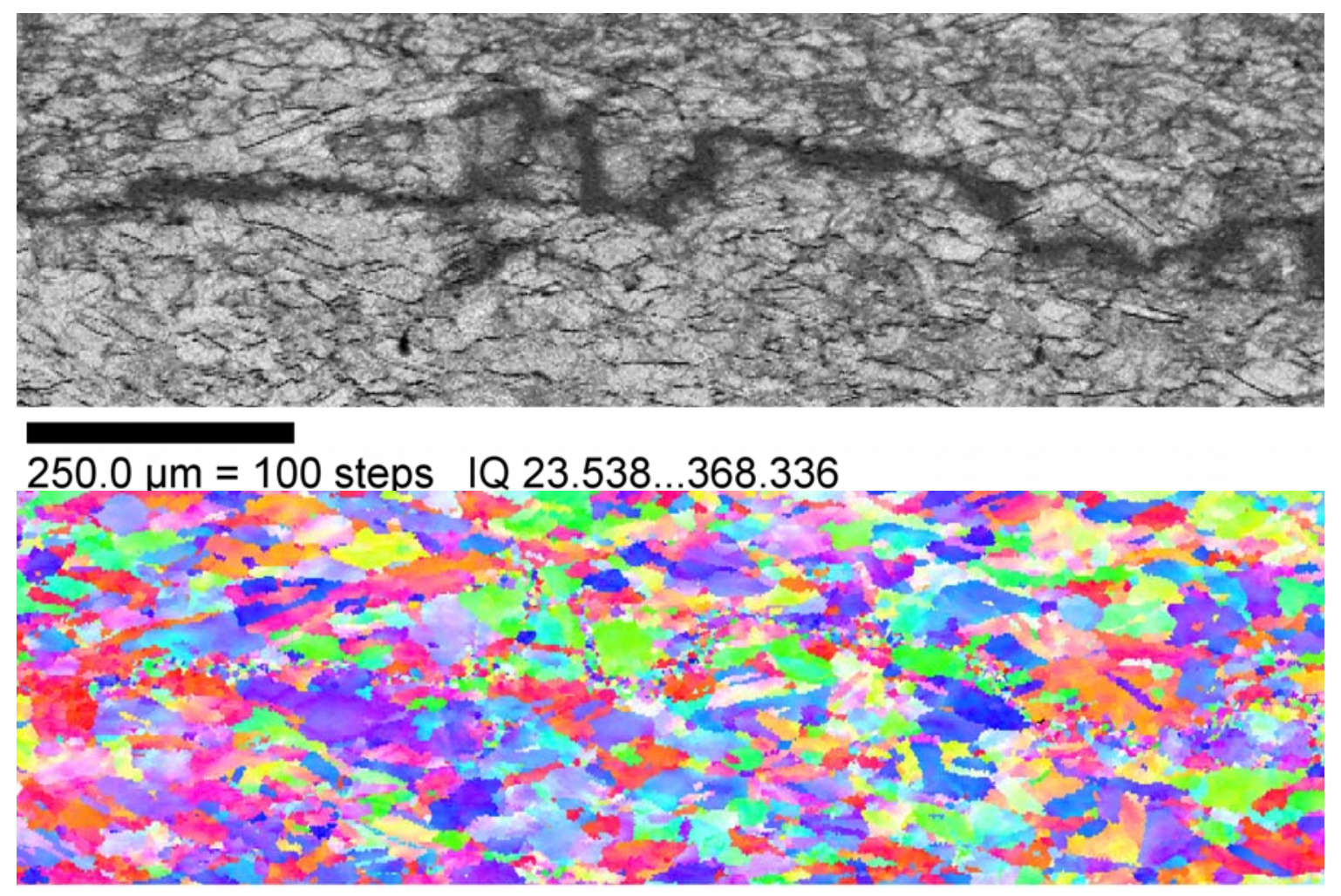

\section{$250.0 \mu \mathrm{m}=100$ steps IPF [001]}

Figure 8. Electron backscatter diffraction images of recompressed $220 \mathrm{~m} / \mathrm{s}$ target: a) image quality and b) grain orientation. 

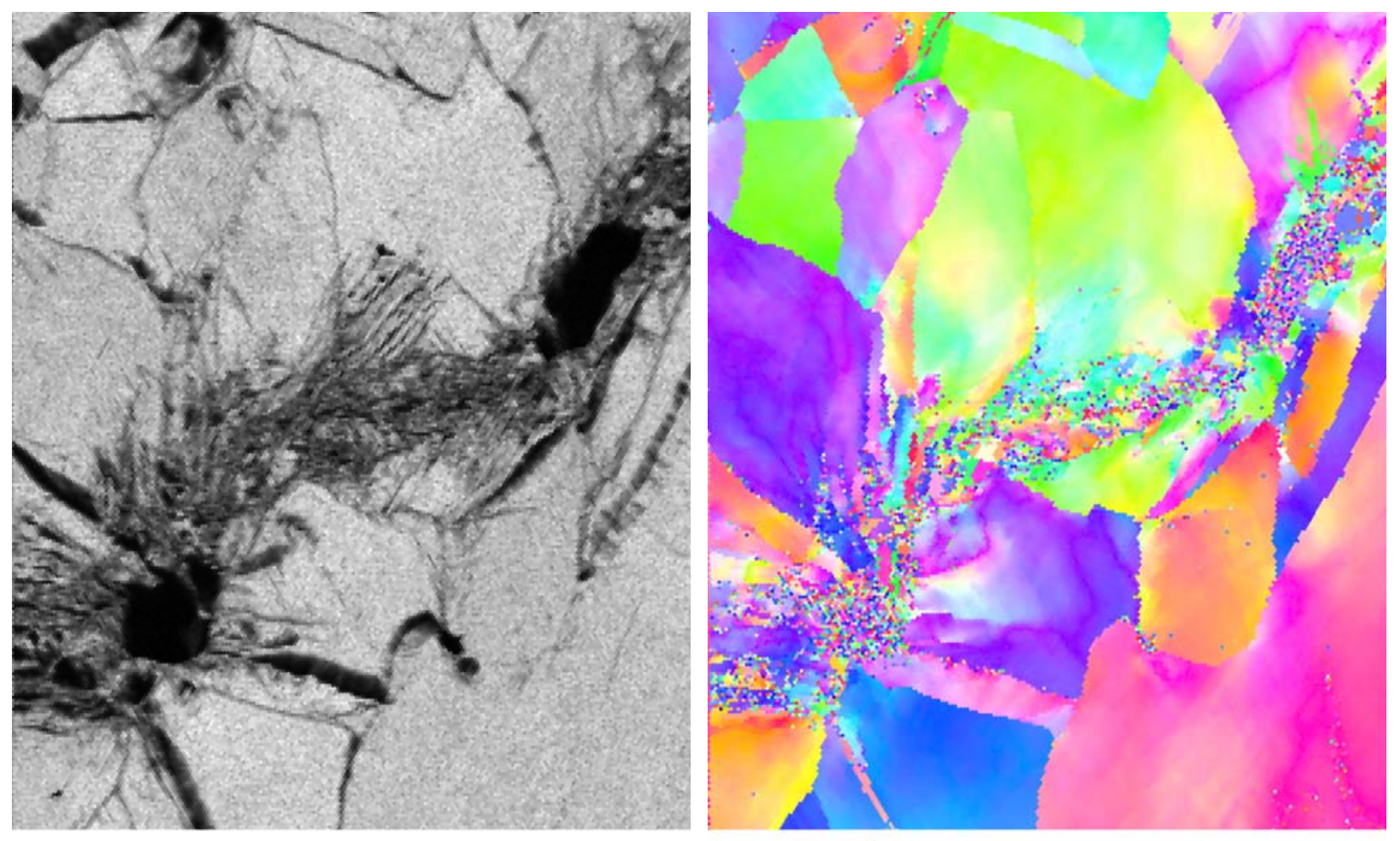

$11.25 \mu \mathrm{m}=45$ steps IQ 20.159 $\ldots 376.53911 .25 \mu \mathrm{m}=45$ steps IPF [001]

Figure 9. Higher resolution electron backscatter diffraction images of recompressed $220 \mathrm{~m} / \mathrm{s}$ target revealing voids and larger grains cut by the prior spall surface: a) image quality and b) grain orientation.

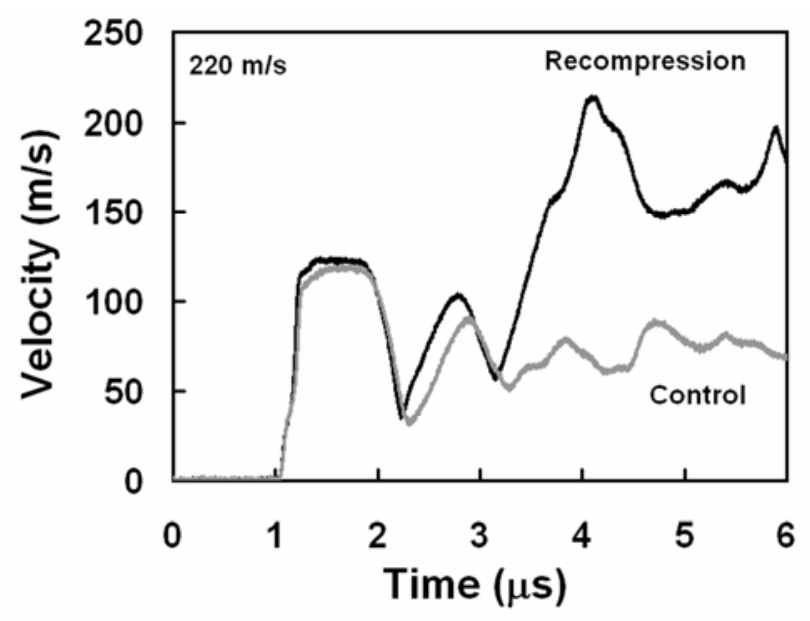

Figure 10. Free surface velocity for the $220 \mathrm{~m} / \mathrm{s}$ tests. 


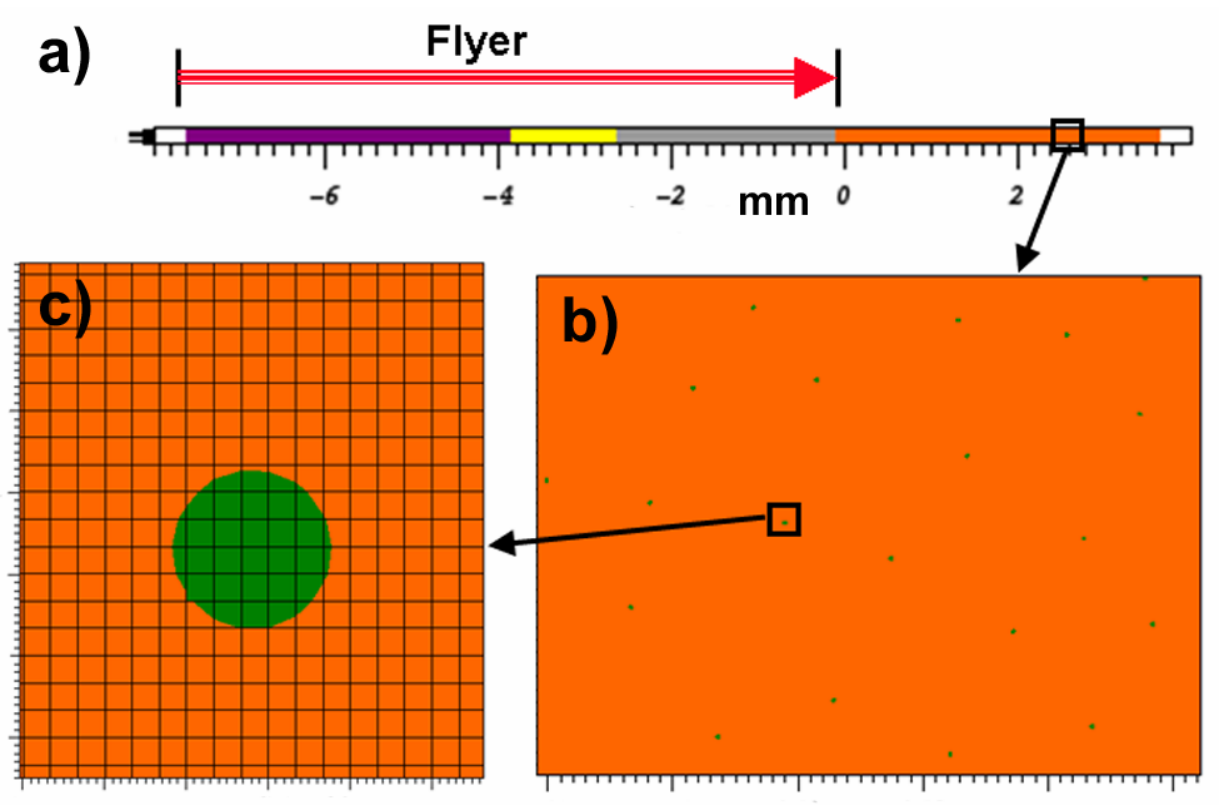

Figure 11. Model description: a) overall geometry, b) particles in the cross section and c) uniform finite element discretization showing resolution of particles. 

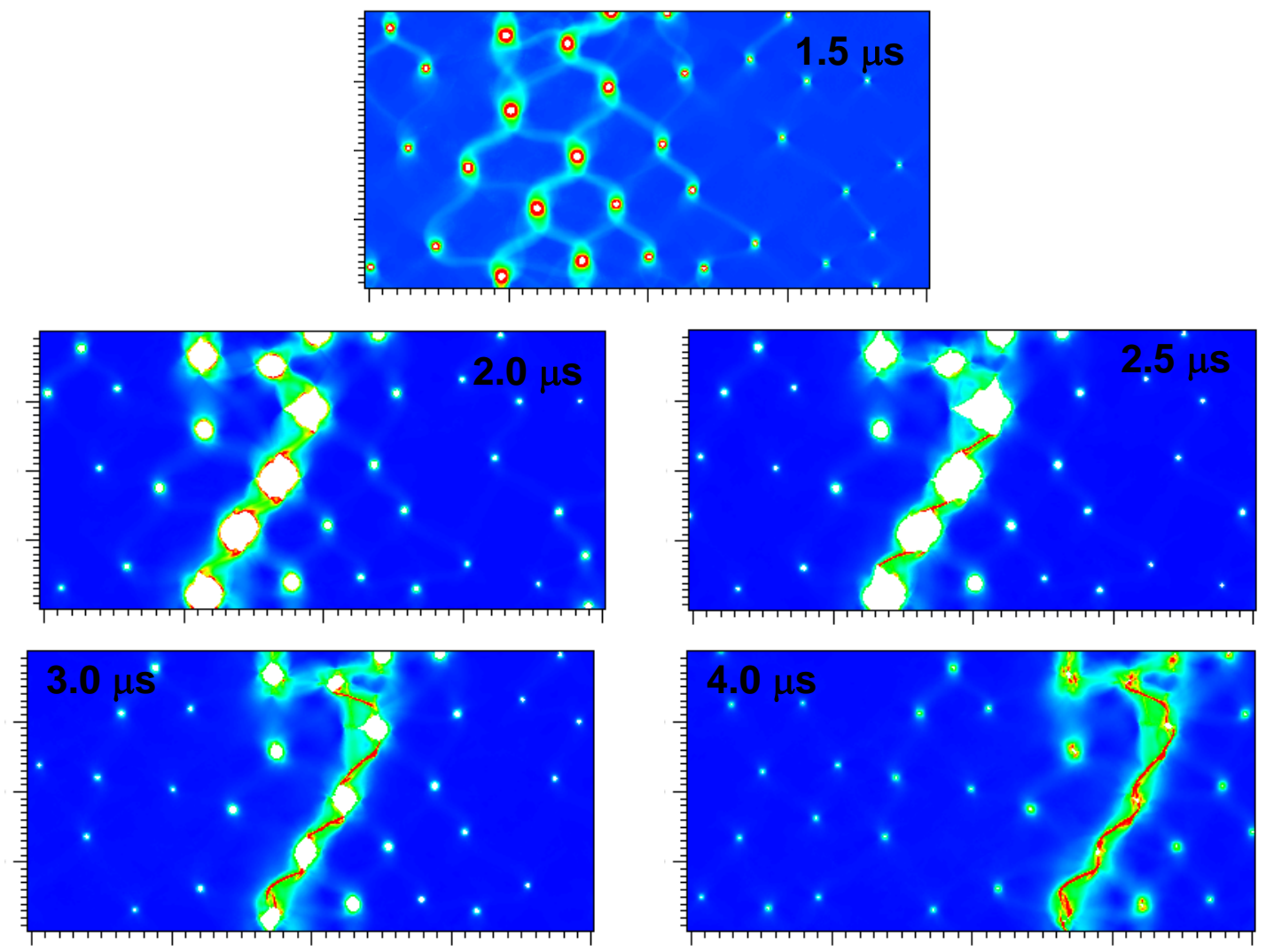

Figure 12. Plastic strain contours at the spall region of the $165 \mathrm{~m} / \mathrm{s}$ simulation. For plots at $2.5 \mu \mathrm{s}$ and beyond the maximum contour level is set at 2.5 to highlight the highly localized nature of the deformation. 

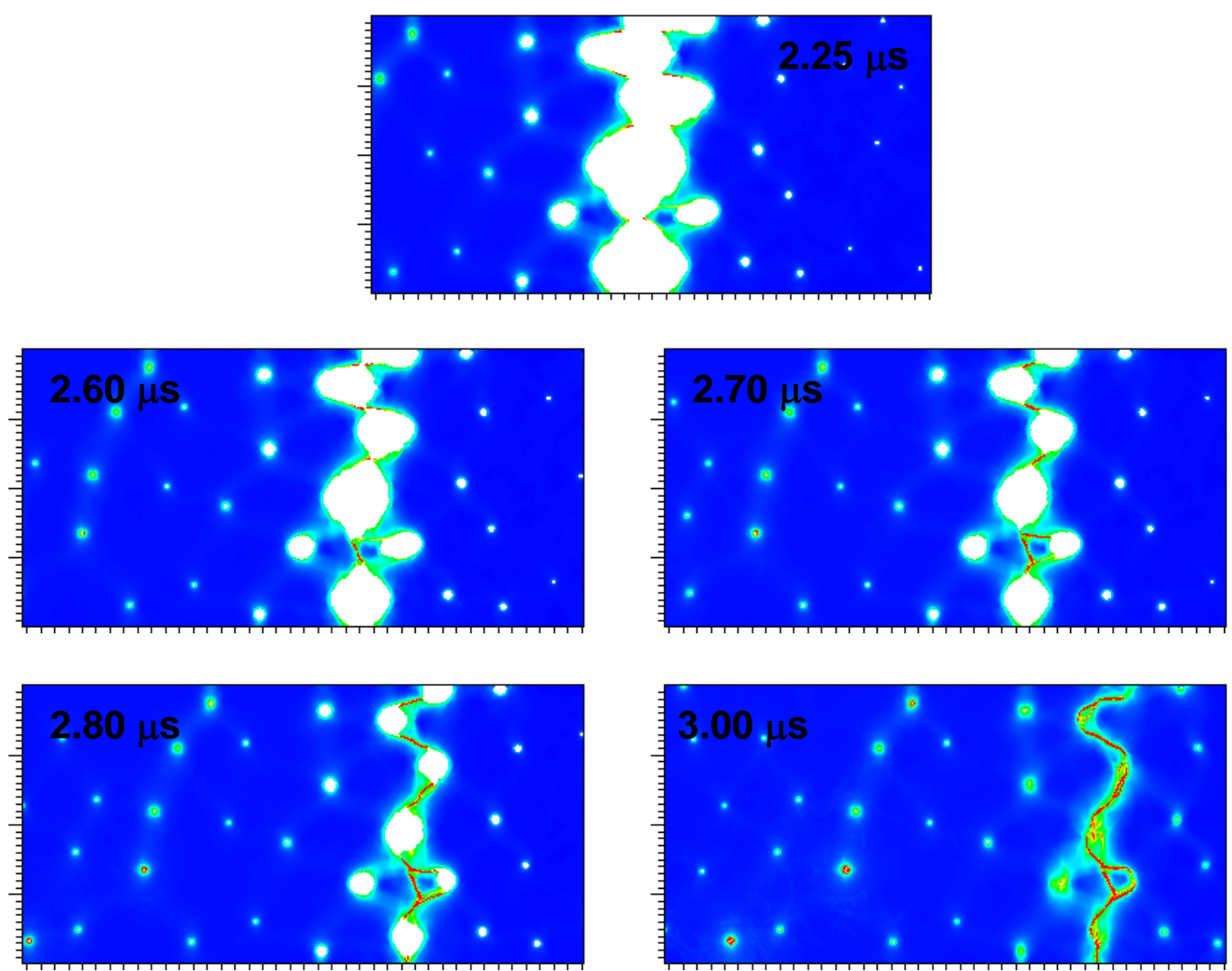

Figure 13. Plastic strain contours at the spall region of the $220 \mathrm{~m} / \mathrm{s}$ simulation. The maximum contour level is set at 4.0 to highlight the highly localized nature of the deformation. 